\title{
Review of Ageing, Lifestyles and Economic Crises. The New People of the Mediterranean, edited by Thierry Blöss, in collaboration with Isabelle Blöss-Widmer, Elena Ambrosetti, Michèle Pagès and Sébastien Oliveau
}

Angela Paparusso (D)

Correspondence: angela. paparusso@irpps.cnr.it Institute for Research on Population and Social Policies (IRPPS-CNR), Via Palestro, 32 - 00185 Rome, Italy
Book details: Thierry Blöss (ed.), in collaboration with Isabelle Blöss-Widmer, Elena Ambrosetti, Michèle Pagès and Sébastien Oliveau, Ageing, Lifestyles and Economic Crises. The New People of the Mediterranean, New York: Routledge; 2018. 276 pages, ISBN: 978-1-138-04026-7.

This miscellaneous book, edited by Thierry Blöss, in collaboration with Isabelle Blöss-Widmer, Elena Ambrosetti, Michèle Pagès and Sébastien Oliveau, is an excellent example of how to deal with a classical topic of Demography-population ageing and its consequences-in an original way.

Three lines of research or "major cross-cutting issues" (p. 1) are addressed in the book, with the aim of highlighting the evolution of lifestyles and life cycles in Mediterranean societies. The lines of research are (1) the ageing of populations and the consequent transformations of life stages, defined according to social groups and to gender categories and considering the territorial dimension; (2) the evolution of intergenerational dynamics and relationships, and the related policies; and (3) the evolution of women's role in the society: both in the family and in the labour market.

This is a book about dynamics and transformations. The principle of family solidarity, individualism versus altruism, family as imperfect institution, division of roles between family and state and, within the family, between men and women, the economic crisis and the produced social vulnerabilities are some of the core topics of the volume. These topics are transversal to the book's three lines of research and, therefore, they are accordingly declined.

The Mediterranean is understood not as a common culture given by a shared history of norms and practices (therefore, not as a normative model), but as a sociologically relevant space: a social context where the transformations inherent to the process of population ageing can be usefully observed and compared. Within this context, four

(c) The Author(s). 2021 Open Access This article is licensed under a Creative Commons Attribution 4.0 International License, which permits use, sharing, adaptation, distribution and reproduction in any medium or format, as long as you give appropriate credit to the original author(s) and the source, provide a link to the Creative Commons licence, and indicate if changes were made. The images or other third party material in this article are included in the article's Creative Commons licence, unless indicated otherwise in a credit line to the material. If material is not included in the article's Creative Commons licence and your intended use is not permitted by statutory regulation or exceeds the permitted use, you will need to obtain permission directly from the copyright holder. To view a copy of this licence, visit http://creativecommons.org/licenses/by/4.0/. 
countries are selected as setting of the empirical research proposed in the volume: Italy, Spain and France (northern shore of the Mediterranean Sea) and Morocco (southern shore of the Mediterranean). Albeit the number of countries could appear small at first sight, at the end of the book the reader will be able to grasp similarities and differences amongst the selected Mediterranean countries, to appreciate transformations, achievements and convergences of behaviours, to understand the asymmetries, improvements and limits of the policies and, finally, to think about future measures, tendencies, and even more important, mentalities.

The three lines of research represent also the sections in which the book is materially organized, whereas the 2007 economic crisis is the chronological division of the entire analysis. Therefore, twelve contributions are offered: four (as the number of countries) for each line of research. The original and multifaceted perspective adopted by the book is enabled, of course, by the multidisciplinary contribution of demographers, geographers, economists and sociologists.

The first part of the book analyses the transformations in the life cycle in terms of the ageing of populations in the Mediterranean societies. In particular, through the study of the demographic transitions experienced by all the area's countries, the authors help to depict a process of convergence amongst the Mediterranean countries, but at the same time to bring out nuances and peculiarities. The latter depend on the different factors that characterize each society's ageing process and on the different policy measures enacted to counteract it. As a consequence, this part of the book allows to understand that the population ageing did not manifest in the same way in the four countries and that it has different implications for the individuals and the societies. However, important common traits exist. For instance, although Italy and Spain's demographic transitions are different, closer to the theoretical model in Italy (Chapter 1) and initially slower (the transition process started only in the early twentieth century) and then faster in Spain, with an accelerated population ageing, also given by a stronger process of secularization (Chapter 2), in both countries, foreign immigration played an important role in slowing down population ageing and the decline in fertility. It is quite alarming both in Italy and Spain the phenomenon of emigration, which involve nationals, naturalized immigrants and new immigrants. Although they are pushed to leave the country of residence by different reasons, the emigration of both nationals and foreigners reveal the loss of attractiveness and competitiveness of Italy and Spain, especially after the economic crisis that has worsen employment conditions (Fellini 2018).

The territorial dimension is central in the analysis of population ageing made for Morocco and France. In the case of Morocco (Chapter 3), important differences between life expectancy of men and women living in urban and rural areas emerge, caused by a different access to health and care services. It is also interesting the reduction of fertility (from 7.2 children per woman in 1962 to 2.2 in 2014), which cannot be explained by an increased access to education of illiterate women (especially in rural areas), but by the desire of women to increase their children's chances of obtaining better education opportunities. This demonstrates that the trade-off between quality and quantity of children is occurring in Morocco too, as in the northern shore of the Mediterranean. Finally, the articulated territorial analysis of population ageing in France (Chapter 4) shows that the rural and the coastline zones host a higher percentage of 
elderly, compared to the urban areas. Coastlines are a source of attraction for retired people, because of the sea, the weather and other amenities.

The second part of the book examines the transformation in the intergenerational dynamics and in the individual and family lifestyles deriving from the population ageing process. This section of the book takes into consideration the role played by the state in these changing dynamics.

The Southern European welfare model is characterized, amongst other things, by a social welfare strongly focused on families (Neyer 2013). The latter compensate for the scarce penetration of the state in social assistance, on the one hand, through substantial intergenerational transfers of monetary and non-monetary resources, above all from parents to adult children and grandchildren; on the other hand, through the almost complete burden of domestic work and care of children and elderly parents on women (Bonifazi and Paparusso 2019). This situation exacerbates gender disparities in the private and professional life (Meggiolaro and Ongaro 2019). On this regard, the Italian analysis of the Southern European welfare model (Chapter 5) reveals a distortion in the distribution of the public expenses, mainly devoted to the pension system and to 'old age' and neglecting some of the other dependent and vulnerable categories, thus demonstrating the limited capability of the Italian system to adapt to the transformations occurred in the intergenerational dynamics and in the individual and family lifestyles.

The economic crisis had an additional impact on the transformation of individual and family behaviours and lifestyles: both the state and the family had to adapt to an increasing ageing population, the first experiencing more difficulties in its level of commitment in providing social protection and the second enacting new strategies, such as cohabitation and intra-family material support, as highlighted for Spain (Chapter 6), where elderly persons are at the same time donors and beneficiaries of family support, and for Morocco (Chapter 7), where despite intergenerational changes, family solidarity remains a solid and efficient institution. On the contrary, the French analysis (Chapter 8), using Share data, shows that the presence of coexisting generations is not necessarily synonymous of mutual support, with the 'pivot' or 'sandwich' generations experiencing problems in adapting to the modified intergenerational relationships.

The third part of the book is devoted to study one of the most important changes in the lifestyles of the Mediterranean societies: the role of women. In an increasing ageing population, women are the most vulnerable: their role as main caregiver reduces their participation to the labour market, including the possibilities of career advancements, influence their reproductive behaviours and affects their own ageing process. Unlike other European countries, in Southern Europe the negative association between female employment rate and total fertility rate has not yet been reversed: whilst the female employment rate have increased over the last decades, although remaining lower than in other European countries, the average number of children per woman fell widely below the replacement level of 2.1 (Pailhé et al. 2019). Preserving women's occupation-also through part-time contracts-before and after the birth of children, and the provision of services for early childhood is therefore of vital importance if we want to reduce the opportunity cost associated with children, especially for more educated women, as clearly stressed for Spain (Chapter 10).

The issue of reconciling private and professional life is extensively examined for Italy (Chapter 9), taking into account the geographical dimension. Finally, Morocco (Chapter 
11) and France (Chapter 12) both highlight the gap that may exist between policies and practices. In France, a country with a long tradition of active family policies, the principle of individualism that advocates for a complete autonomy and selfdetermination of the person within the society, remains however quite gender-biased, 'reinforcing both the role of women as principal caregivers and the role of men as the main income providers' (p. 266). Similarly, in Morocco, the improvement of public policies towards more gender equality in private and public life and the spread of modern views still collide with traditional lifestyles, which tend to reinforce gender bias in education, in employment and in the family context.

If I have to mention two weak points of the book, (1) as often occurs in collective volumes, there are some repetitions in the introduction of some contributions that could have been avoided; (2) other countries of the southern shore of the Mediterranean could have been considered, in order to have a more complete and balanced picture of the topics addressed in the book.

Nevertheless, the multidisciplinary, documented and well-written book edited by Thierry Blöss is not only a good illustration of the main consequences of the population ageing process in some Mediterranean societies, but it is also a useful tool to understand what has been and what still needs to be done to adapt our societies to the current socio-demographic transformations. The process of adaptation needs both private and public engagement and it passes through a radical change of mentality. A mentality of equality, solidarity, subsidiarity, and participation should be adopted. Citizens and policymakers should bear in mind that reforms are generally ineffective if behaviours and institutions do not adjust in the long-term (e.g. Vignoli et al. 2020).

Acknowledgements

Not applicable (book review)

Author's contributions

Only one author. The author read and approved the final manuscript.

Funding

I did not receive any funding for this publication.

Availability of data and materials

Not applicable (book review)

Competing interests

The author declares that she has no competing interests in the manuscript.

Received: 7 January 2021 Accepted: 28 January 2021

Published online: 03 February 2021

\section{References}

Bonifazi, C., \& Paparusso, A. (2019). L'impatto delle politiche familiari sulla bassa fecondità europea [The impact of family policies on Europe's low fertility]. La Rivista delle Politiche Sociali, 4, 31-49.

Fellini, I. (2018). Immigrants' labour market outcomes in Italy and Spain: Has the southern European model disrupted during the crisis? Migration Studies, 6(1), 53-78.

Meggiolaro, S., \& Ongaro, F. (2019). The involvement in childcare of married and co-habiting fathers: Evidence from Italy. Genus, 75(3), 1-19.

Neyer, G. (2013). Welfare states, family policies, and fertility in Europe. In G. Neyer, G. Andersson, H. Kulu, L. Bernardi, \& C. Bühler (Eds.), The demography of Europe, (pp. 29-53). Dordrecht: Springer.

Pailhé, A., Solaz, A., \& Tanturri, M. L. (2019). The time cost of raising children in different fertility contexts: Evidence from France and Italy. European Journal of Population, 35(2), 223-261.

Vignoli, D., Guetto, R., Bazzani, G., Pirani, E., \& Minello, A. (2020). A reflection on economic uncertainty and fertility in Europe: The narrative framework. Genus, 76(1), 1-27. 